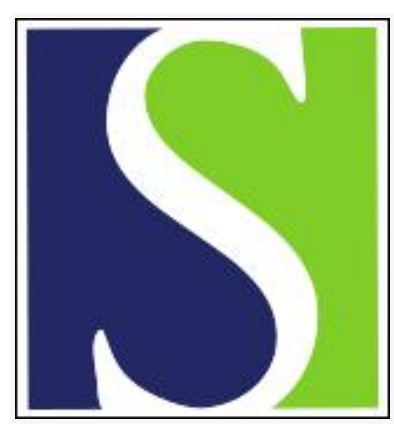

Scand J Work Environ Health 1993;19(4):245-254

https://doi.org/10.5271/sjweh.1477

Issue date: 01 Aug 1993

Effects of occupational exposure to organic solvents and noise on hearing.

by Morata TC, Dunn DE, Kretschmer LW, Lemasters GK, Keith RW

Affiliation: Department of Communication Sciences and Disorders, University of Cincinnati, Ohio.

This article in PubMed: www.ncbi.nlm.nih.gov/pubmed/8235513

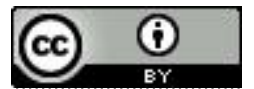




\title{
Effects of occupational exposure to organic solvents and noise on hearing
}

\author{
by Thais C Morata, PhD, ${ }^{1}$ Derek E Dunn, $\mathrm{PhD},{ }^{2}$ Laura W Kretschmer, EdD, ${ }^{1}$ \\ Grace K Lemasters, PhD, ${ }^{3}$ Robert W Keith, $\mathrm{PhD}^{1}$
}

\begin{abstract}
MORATA TC, DUNN DE, KRETSCHMER LK, LEMASTERS GK, KEITH RW. Effects of occupational exposure to organic solvents and noise on hearing. Scand J Work Environ Health 1993;19:24554. This study explored the effects of occupational exposure to solvents and noise on hearing. Interviews and hearing tests were conducted for printing and paint manufacturing workers. The experimental groups included unexposed $(\mathrm{N}=50)$ workers and workers exposed to noise $(\mathrm{N}=50)$, noise and toluene $(\mathrm{N}=51)$, or an organic solvent mixture $(\mathrm{N}=39)$. The risk of hearing loss was greater for the exposed groups than for the unexposed group. The adjusted relative risk estimates were four times greater [95\% confidence interval $(95 \% \mathrm{CI}) 1.4-12.2]$ for the noise group, 11 times greater $(95 \% \mathrm{CI}$ $4.1-28.9)$ for the noise and toluene group, and five times greater $(95 \% \mathrm{CI} 1.4-17.5)$ for the solvent-mixture group. The findings suggest that exposure to the studied solvents had a toxic effect on the auditory system and that an interaction between noise and toluene took place. The audiological results of the noise and toluene group suggest a central auditory pathway involvement in the hearing losses observed.
\end{abstract}

Key terms: auditory system, interaction, paint manufacturing, rotogravure printers, toluene, xylene.

Hearing loss is still one of the most prevalent occupational diseases in the United States and most other industrialized countries $(1-3)$. In the United States at least one million workers in manufacturing are estimated to have sustained job-related hearing impairment, and about a half million of these workers have moderate to severe hearing impairment (1). Occupational hearing loss has long been recognized as a direct health effect of overexposure to noise, but only recently has exposure to solvents been considered as a contributor to the development of hearing impairment $(4-10)$. There is evidence which suggests that noise interacts synergistically with various drugs and chemicals $(11-18)$. Evidence is also beginning to accumulate which suggests that an ototraumatic interaction may exist between noise and organic sol-

' Department of Communication Sciences and Disorders, University of Cincinnati, Cincinnati, Ohio, United States.

2 Department of Environmental Health, University of Cincinnati, Cincinnati, Ohio, United States.

3 United States Department of Health Human Services, Public Health Service, Centers for Disease Control, National Institute for Occupational Safety and Health Division of Biomedical and Behavioral Science Physical Agents Effects Branch, Cincinnati, Ohio, United States.

Reprint requests to: Dr TC Morata, Visiting Scientist, National Institute for Occupational Safety and Health, Bioacoustics and Occupational Vibration Section, Division of Biomedical and Behavioral Science, 4676 Columbia Parkway/MS C27, Cincinnati, OH 45226-1998, USA. vents. Data on the ototoxic effects of solvents like toluene, xylene, and styrene come mainly from limited animal studies and case reports on substance abusers (19-24).

Such ototraumatic interaction was suggested in 1984 , when its biological plausibility was discussed. It has been observed that the incidence of sensorineural hearing loss was higher than expected in workers exposed to solvents. Organic solvents are well known for their neurotoxic effects, which, in exposed workers, can give rise to both central and peripheral injuries in the nervous system. It has been hypothesized that solvents can injure the sensory cells and peripheral nerve endings of the cochlea, and, considering known solvent-related effects on the brain, a retrocochlear influence can also be expected (4).

In a 20-year longitudinal study of the hearing sensitivity of 319 employees, it was observed that $23 \%$ of the workers from a chemical division showed pronounced hearing loss through exposure to lower noise levels [80-90 $\mathrm{dB}(\mathrm{A})]$ as compared with 5$8 \%$ of workers from nonchemical environments with exposure to higher noise levels [95-100 $\mathrm{dB}(\mathrm{A})](5)$.

In the present study we evaluated, using pure tone audiometry, the occurrence of hearing disorders in groups of workers (i) not exposed to noise or organic solvents, (ii) exposed to noise, (iii) exposed to noise and toluene, and (iv) exposed to a mixture of solvents including toluene. Moreover, acoustic reflex measurements were performed with the objective of obtaining information concerning the anatomic location of the observed hearing disorders. 


\section{Subjects and methods}

Study design

To investigate the effects of occupational exposure to noise and solvents on workers' hearing, we interviewed samples of Brazilian workers from the printing and paint manufacturing industries, tested their hearing, and assessed their exposure to both agents. Male workers employed for a minimum of one year were included.

\section{Study population}

At the printing plant, groups of workers from three divisions, (preparation, rotogravure printing, and finishing and binding) were randomly selected to participate. Workers were selected from the preparation division to serve as an unexposed comparison group, as they were not occupationally exposed to any known or suspected ototoxicant. These workers were involved in setup operations that included graphic arts, composition, photocomposition, scanner operation, offset, and retouching. Both retrospective and current sound pressure measurements in this division indicated that the noise levels were in a range that was assumed not to pose a hazard to employees' hearing [below $85 \mathrm{~dB}(\mathrm{~A})$ ].

Workers selected from the finishing and binding division served as the noise-only exposure group. The work activities included cutting, trimming, collating, and binding magazines. Sound pressure measurements conducted during the present investigation in this division were in agreement with the industry's historical records. These measurements showed continuous noise levels in the range of $88-97$ $\mathrm{dB}(\mathrm{A})$. Noise dosimetry indicated levels that ranged from 209 to $335 \%$. The recommended limit of $85 \mathrm{~dB}(\mathrm{~A})$ and the $5-\mathrm{dB}$ exchange rate were used in this evaluation. No hearing protectors were used.

Workers were selected from the rotogravure printing division because of their exposure to both excessive levels of noise and toluene ( $98 \%$ purity). Sound pressure measurements showed noise levels in the range of $88-98 \mathrm{~dB}(\mathrm{~A})$. Noise dosimetry revealed doses ranging from 140 to $350 \%$. To evaluate toluene exposure, historical data obtained by the com- pany using color indicator tubes (Draeger) and data collected by the present investigation (March 1990) using SKC charcoal tubes and Dupont air pumps (model P 4000) were used. The results are shown in table 1. An assessment of toluene exposure was first made in July 1978. A ventilation system was installed by September 1978. The results of the measurements obtained in the present study, analyzed through gas chromatography, are displayed in the 1990 column of table 1 .

Those who worked during 1978 while the ventilation system was being installed were exposed to extremely high concentrations of toluene. A level of $1860 \mathrm{ppm}$ of toluene was once registered in 1978 . It can be observed in table 1 that, after the ventilation system was installed, the concentrations of toluene in the air decreased, but they are still excessive when compared with the recommended threshold limit value (100 ppm).

At the paint manufacturing plant, the fourth group of workers, exposed to a mixture of solvents but not noise, was randomly selected from the filling division. Their work activities included placing cans on conveyor belts, controlling their filling, and closing and labeling them. These workers were exposed to a mixture of organic solvents that contained toluene. The noise levels registered in this division were below the recommended limit of $85 \mathrm{~dB}(\mathrm{~A})$. The major components in the mixture of solvents were toluene, xylene, methyl ethyl ketone, and methyl isobutyl ketone, but their relative proportion varied. On three different occasions organic solvents were measured in the mixture through passive sampling with samplers from the Minnesota, Mining and Manufacturing Company, type 3500 . The concentration of the mixture in the air, relative to their respective threshold limit values (TLV) was calculated according to the formula of the American Conference of Governmental Industrial Hygienists and the Brazilian threshold limits.

The results displayed in table 2 indicate that for three of eleven samples the recommended concentration limit for mixtures was exceeded. It should be noted that for eight of the eleven samples toluene had the highest concentration. In addition, this division had no ventilation system.

Table 1. Time-weighted average (TWA) concentrations of toluene in the rotogravure printing division.

\begin{tabular}{|c|c|c|c|c|c|c|c|c|c|c|}
\hline \multirow[b]{2}{*}{ Section } & \multicolumn{2}{|c|}{ July 1978} & \multicolumn{2}{|c|}{ September 1978} & \multicolumn{2}{|c|}{ March 1979} & \multicolumn{2}{|c|}{ March 1980} & \multicolumn{2}{|c|}{ March 1990} \\
\hline & $\begin{array}{c}\text { Number } \\
\text { of } \\
\text { samples }\end{array}$ & $\begin{array}{l}\text { TWA } \\
\text { (ppm) }\end{array}$ & $\begin{array}{l}\text { Number } \\
\text { of } \\
\text { samples }\end{array}$ & $\begin{array}{l}\text { TWA } \\
\text { (ppm) }\end{array}$ & $\begin{array}{c}\text { Number } \\
\text { of } \\
\text { samples }\end{array}$ & $\begin{array}{l}\text { TWA } \\
\text { (ppm) }\end{array}$ & $\begin{array}{c}\text { Number } \\
\text { of } \\
\text { samples }\end{array}$ & $\begin{array}{l}\text { TWA } \\
\text { (ppm) }\end{array}$ & $\begin{array}{l}\text { Number } \\
\text { of } \\
\text { samples }\end{array}$ & $\begin{array}{l}\text { TWA } \\
\text { (ppm) }\end{array}$ \\
\hline 1 & 2 & 315 & 5 & 140 & - & . & - & . & 4 & 100 \\
\hline 2 & $4^{a}$ & 600 & 13 & 240 & 2 & 200 & $13^{a}$ & 370 & 4 & 280 \\
\hline 3 & 1 & 265 & 6 & 253 & 2 & 150 & 2 & 150 & 3 & 75 \\
\hline 4 & - & . & - & . & - & $\cdot$ & - & $\cdot$ & 3 & 100 \\
\hline 5 & - & . & - & . & - & . & - & . & 8 & 365 \\
\hline
\end{tabular}

a Concentrations above $1000 \mathrm{ppm}$ were observed. 
Due to the lack of historical data from this division and the restricted access of the authors to plant operations, the results displayed by table 2 are insufficient to allow an extensive evaluation of worker exposure.

To determine whether underlying differences might have existed between the studied groups, we assessed previous exposure to noise, previous exposure to chemicals, medical and audiological history, hobby history, and prior military service. The characteristics of the four study populations are presented in table 3.

The mean length of employment for workers from the printing plant was 8 to 13 years; for the paint manufacturing plant it was about six years $(\mathrm{F}=$ $11.54, \mathrm{P}<0.01)$. Overall, the study groups comprised a fairly young sample of employees. The age of the workers in all of the groups was also similar to the mean age in years, ranging from about 32 to 36 years. In the analysis, age was not included as a risk factor due to the similarities of the groups and because it was correlated with the length of employment (ie, the longer one works the older he or she becomes).

\section{Questionnaire}

A standardized medical and work history questionnaire was developed with major portions extracted

Table 2. Solvent concentrations in the paint filling division.

\begin{tabular}{|c|c|c|c|c|c|c|c|}
\hline Sample & $\begin{array}{l}\text { Toluene } \\
\text { (ppm) }\end{array}$ & $\begin{array}{l}\text { Xylene } \\
\text { (ppm) }\end{array}$ & $\begin{array}{c}\text { Benzene } \\
\text { (ppm) }\end{array}$ & $\begin{array}{l}\text { Methyl ethyl } \\
\text { ketone } \\
\text { (ppm) }\end{array}$ & $\begin{array}{l}\text { Methyi } \\
\text { isobutyl } \\
\text { ketone } \\
\text { (ppm) }\end{array}$ & $\begin{array}{l}\text { Ethanol } \\
\text { (ppm) }\end{array}$ & $\begin{array}{c}\text { Summed } \\
\text { concentration }^{a}\end{array}$ \\
\hline 1 & 70 & 40 & 2 & 0 & 0 & 10 & 1.59 \\
\hline 2 & 35 & 12 & 0.2 & 0 & 0 & 8 & 0.59 \\
\hline 3 & 28 & 18 & 0.3 & 0 & 7 & 16 & 0.77 \\
\hline 4 & 15 & 25 & 0 & 22 & 8 & 0 & 0.77 \\
\hline 5 & 10 & 16 & 0 & 15 & 4 & 0 & 0.50 \\
\hline 6 & 17 & 23 & 0 & 32 & 20 & 0 & 1.11 \\
\hline 7 & 33 & 15 & 0 & 21 & 17 & 0 & 1.08 \\
\hline 8 & 28 & 18 & 0.2 & 0 & 7 & 15 & 0.75 \\
\hline 9 & 25 & 15 & 2 & 0 & 12 & 9 & 0.78 \\
\hline 10 & 43 & 17 & 0.2 & 12 & 7 & 0 & 0.99 \\
\hline 11 & 42 & 17 & 0.2 & 0 & 0 & 0 & 0.73 \\
\hline
\end{tabular}

a Relative to the threshold limit values.

Table 3. Characterization of the study population - means and standard deviations for the variables age, length of employment, length of previous exposure to noise, length of previous exposure to chemicals, medical and aural history items, hobby history items, and prior military service, by group.

\begin{tabular}{|c|c|c|c|c|c|c|c|c|}
\hline \multirow{3}{*}{ Variable } & \multicolumn{8}{|c|}{ Group } \\
\hline & \multicolumn{2}{|c|}{ Unexposed } & \multicolumn{2}{|c|}{ Noise only } & \multicolumn{2}{|c|}{$\begin{array}{l}\text { Noise }+ \text { toluene } \\
\text { exposure }\end{array}$} & \multicolumn{2}{|c|}{$\begin{array}{l}\text { Solvent mixture } \\
\text { exposure }\end{array}$} \\
\hline & Mean & SD & Mean & SD & Mean & SD & Mean & SD \\
\hline Age (years) & 34.7 & 9.8 & 36.1 & 8.2 & 32.5 & 7.9 & 31.7 & 7.2 \\
\hline Length of employment (years) & 13.1 & 7.6 & 11.6 & 7.8 & 8.1 & 6.2 & 5.6 & 3.7 \\
\hline $\begin{array}{l}\text { Length of previous noise } \\
\text { exposure (years) }\end{array}$ & 0.5 & 1.5 & 1.2 & 2.5 & 1.2 & 2.2 & 1.3 & 2.6 \\
\hline $\begin{array}{l}\text { Length previous chemical } \\
\text { exposure (years) }\end{array}$ & 1.6 & 2.7 & 1.0 & 2.6 & 1.4 & 2.7 & 0.9 & 2.5 \\
\hline Diabetes (proportion) & 0.02 & 0.1 & 0 & 0 & 0.01 & 0.1 & 0 & 0 \\
\hline Hypertension (proportion) & 0.02 & 0.1 & 0.10 & 0.3 & 0.03 & 0.2 & 0.05 & 0.2 \\
\hline Ear infection (proportion) & 0.26 & 0.4 & 0.18 & 0.3 & 0.15 & 0.3 & 0.10 & 0.3 \\
\hline $\begin{array}{l}\text { Ototoxic medication usage } \\
\text { (proportion) }\end{array}$ & 0 & 0 & 0 & 0 & 0 & 0 & 0 & 0 \\
\hline $\begin{array}{l}\text { Hunting/shooting } \\
\text { (proportion) }\end{array}$ & 0.32 & 0.7 & 0.44 & 0.7 & 0.28 & 0.6 & 0.30 & 0.6 \\
\hline Motor sports (proportion) & 0.10 & 0.3 & 0 & 0 & 0.07 & 0.3 & 0.02 & 0.1 \\
\hline $\begin{array}{l}\text { Amplified music } \\
\text { (proportion) }\end{array}$ & 0.14 & 0.3 & 0.06 & 0.2 & 0.07 & 0.2 & 0.05 & 0.2 \\
\hline Power tools (proportion) & 0.14 & 0.3 & 0.18 & 0.3 & 0.13 & 0.3 & 0.10 & 0.3 \\
\hline $\begin{array}{l}\text { Military service } \\
\text { (proportion) }\end{array}$ & 0.12 & 0.3 & 0.06 & 0.2 & 0.09 & 0.3 & 0 & 0 \\
\hline
\end{tabular}


from a questionnaire of the National Institute for Occupational Safety and Health and from various clinical questionnaires. The final version of the questionnaire was translated to Portuguese. Included in the medical portion were questions concerning demographic data, health information that focused on events that could be related to hearing status, and nonoccupational noise-exposure data. A work history was collected which included job descriptions and exposure to noise and chemicals.

The 12-page questionnaire was administered by 11 persons who were either graduate students in audiology or qualified audiologists. All of the interviewers were unaware of the individual's exposure group. To minimize interviewer bias, all of the health questions (including those on hearing) were asked prior to the questions on work history.

\section{Data analysis}

The data from the questionnaire and the test results were entered into dBase III Plus and data files using a program written in Clipper. Extensive checks and rechecks were made for illogical codes or consistency errors. After correction a clean data file was ready for analysis. The data were analyzed with the use of the statistical analysis system (SAS, version $5,1985)$. The data were analyzed with multivariate and univariate analyses of variance. Analyses of association between the hearing status and exposure conditions were also performed. Logistic regression was used for estimating relative risk, adjusted for confounding variables.

\section{Testing procedures}

Pure tone audiometry. To assess the workers' hearing status, otoscopy, pure tone audiometry, and immittance audiometry were performed. Otoscopy was performed to screen for conditions that would exclude the person from the study. All of the subjects were interviewed with regard to health history, work history, and solvent and noise exposure. The tests were performed by audiologists under the principal investigator's supervision. All of the subjects underwent pure tone audiometry at the frequencies of 0.5 , $1,2,3,4,6$, and $8 \mathrm{kHz}$ for air conduction. When

Table 4. Audiometric classification criteria.

\begin{tabular}{lcc}
\hline $\begin{array}{l}\text { Level of high- } \\
\text { frequency hearing } \\
\text { loss }\end{array}$ & $\begin{array}{c}\text { Average of } \\
\text { threshold at } \\
0.5,1 \text { and } 2 \mathrm{kHz} \\
\text { (dB) }\end{array}$ & $\begin{array}{c}\text { Range of the } \\
\text { binaural average } \\
\text { of the pure-tone } \\
\text { threshold of } \\
\text { frequencies at } \\
3-8 \mathrm{kHz} \\
\text { (dB) }\end{array}$ \\
\hline 0 & $0-25$ & $0-25$ \\
I & $0-25$ & $30-40$ \\
II & $0-25$ & $45-55$ \\
III & $0-25$ & 60 up \\
IV & $>25$ & - \\
V-C or V-U & conductive or unilateral hearing loss \\
\hline
\end{tabular}

there was an indication of conductive hearing loss, bone conduction testing was performed. The subjects were tested in a sound-isolated chamber which met the requirements of the American National Standards Institution (ANSI S 3.1.-1991) for audiometric testing environments. The audiometers used were a Medical Acoustics Instruments Company MA4l and a Danavox DB23, and both underwent electroacoustic calibration a week before the data collection started. Biological calibration checks were also performed every day immediately before the subjects were tested.

The high-frequency hearing losses were classified by severity, into categories I through IV according to criteria described elsewhere $(9,25)$. The thresholds in the frequency ranges 0.5 to $2 \mathrm{kHz}$ were averaged. The interaural threshold average of the most affected frequency in the 3 to $8 \mathrm{kHz}$ frequency range was considered when a classification was assigned to the audiograms. A nonoccupational category was included to account for those hearing losses that could not be attributed to occupational factors. The $\mathrm{V}$-C category is for conductive hearing losses, while the V-U category is for unilateral hearing losses. (See table 4.)

Immittance audiometry. Immittance audiometry, another routine battery of tests at the audiology clinic, was performed on all of the subjects. It consisted of tympanometry, static compliance, crossed and uncrossed acoustic reflex testing (at frequencies $0.5,1$, and $2 \mathrm{kHz}$ ), a reflex decay test (at frequencies 0.5 , 1 , and $2 \mathrm{kHz}$ ) and a physical volume test. The main objective in performing immittance audiometry was to obtain information on lesion sites through the investigation of the acoustic reflex findings in the studied groups. The acoustic reflex tests were chosen because of their reliability and availability and because they can be performed in a few minutes. The immittance audiometers used were Interacoustics AZ7 and Damplex ZA28. Both underwent electroacoustic calibration a week before the data collection started and biological calibration every morning before the subjects were tested.

\section{Results}

Each audiogram was evaluated for hearing loss according to the criteria described in table 4 . The audiograms classified as normal were identified by the code $\mathrm{O}$. The presence of a high-frequency, bilateral hearing loss was coded from level I (mild hearing loss) to IV (profound hearing loss). The information provided by the bone conduction audiometry and tympanometry was used to classify hearing loss as conductive. Conductive hearing loss was identified by the V-C code. Unilateral hearing loss was identified as V-U. Table 5 shows the audiometric results of all the subjects by code. 
The prevalence of high-frequency hearing loss in the group exposed to noise and toluene simultaneously $(53 \%)$ was higher than in the other groups (table 4): $8 \%$ in the unexposed group, $26 \%$ in the noiseexposed group, and $18 \%$ in the group exposed to a mixture of solvents. The prevalence of high-frequency hearing loss observed in the solvent-mixture group (18\%) was two times higher than in the unexposed group (8\%).

No statistically significant differences were observed between the groups for the classifications $\mathrm{V}-\mathrm{C}$ and $\mathrm{V}-\mathrm{U}$ (conductive or unilateral hearing losses). A one-way analysis of variance comparing the means of the classification $O$ (normal hearing) for the studied groups indicated that they were significantly different $(\mathrm{P}<0.001)$. The results of the analyses of variance indicated that the group exposed to noise plus toluene had significantly more workers with mild hearing losses (classified as level I) than did all of the other groups $(\mathrm{P}<0.001)$. No statistically significant differences were observed between the groups for the audiogram classifications of II, III, and IV. The percentages of several audiometric classifications [with $\mathrm{T}$ bars indicating upper bounds of $95 \%$ confidence intervals $(95 \% \mathrm{CI})$ ] are displayed in figure 1 by group. All of the subjects were included in the analysis $(\mathrm{N}=190)$.
Analysis of association between hearing status and exposure conditions

The next analysis combined classifications I to IV and analyzed hearing loss as a dichotomous variable (yes/no). The high-frequency hearing losses were examined with a multiple logistic regression. For this analysis, conductive and unilateral hearing losses were entered as normal hearing, since they could not be clearly related to the occupational exposures. This test was conducted to estimate the relative risk adjusted for confounding variables. The variables considered for inclusion in the model were exposure group, length of employment, previous occupational exposure to noise or to chemicals, and exposure to nonoccupational noise. Age was not included because it was highly correlated with the exposure variable length of employment, and the study population was relatively young (median age 33 years). The approaches used were the stepwise forward and backward logistic regression. The only variable that met the significance level criterion for inclusion in the model, besides exposure group, was length of employment. Table 6 gives the results of the final multiple logistic regression model selected by the stepwise procedure, with the relative risk estimates for developing a hearing loss, as adjusted for length of employment (26). The predicted probability of each

Table 5. Number and percentage of the various audiometric classifications, by group.

\begin{tabular}{|c|c|c|c|c|c|c|c|c|c|c|}
\hline \multirow{3}{*}{ Group } & \multicolumn{8}{|c|}{ Audiometric classifications } & \multirow{2}{*}{\multicolumn{2}{|c|}{ Total }} \\
\hline & \multicolumn{2}{|c|}{0} & \multicolumn{2}{|c|}{ I-IV } & \multicolumn{2}{|c|}{ V-C } & \multicolumn{2}{|c|}{$\mathrm{V}-\mathrm{U}$} & & \\
\hline & $\mathbf{N}$ & $\%$ & $\mathrm{~N}$ & $\%$ & $\mathbf{N}$ & $\%$ & $N$ & $\%$ & $N$ & $\%$ \\
\hline $\begin{array}{l}\text { Unexposed } \\
\text { Noise exposed } \\
\text { Noise + toluene exposed } \\
\text { Solvent mixture exposed }\end{array}$ & $\begin{array}{l}36 \\
26 \\
19 \\
28\end{array}$ & $\begin{array}{l}72 \\
52 \\
37 \\
72\end{array}$ & $\begin{array}{r}4 \\
13 \\
27 \\
7\end{array}$ & $\begin{array}{r}8 \\
26 \\
53 \\
18\end{array}$ & $\begin{array}{l}1 \\
2 \\
1 \\
2\end{array}$ & $\begin{array}{l}2 \\
4 \\
2 \\
5\end{array}$ & $\begin{array}{l}9 \\
9 \\
4 \\
2\end{array}$ & $\begin{array}{r}18 \\
18 \\
8 \\
5\end{array}$ & $\begin{array}{l}50 \\
50 \\
51 \\
39\end{array}$ & $\begin{array}{l}100 \\
100 \\
100 \\
100\end{array}$ \\
\hline
\end{tabular}

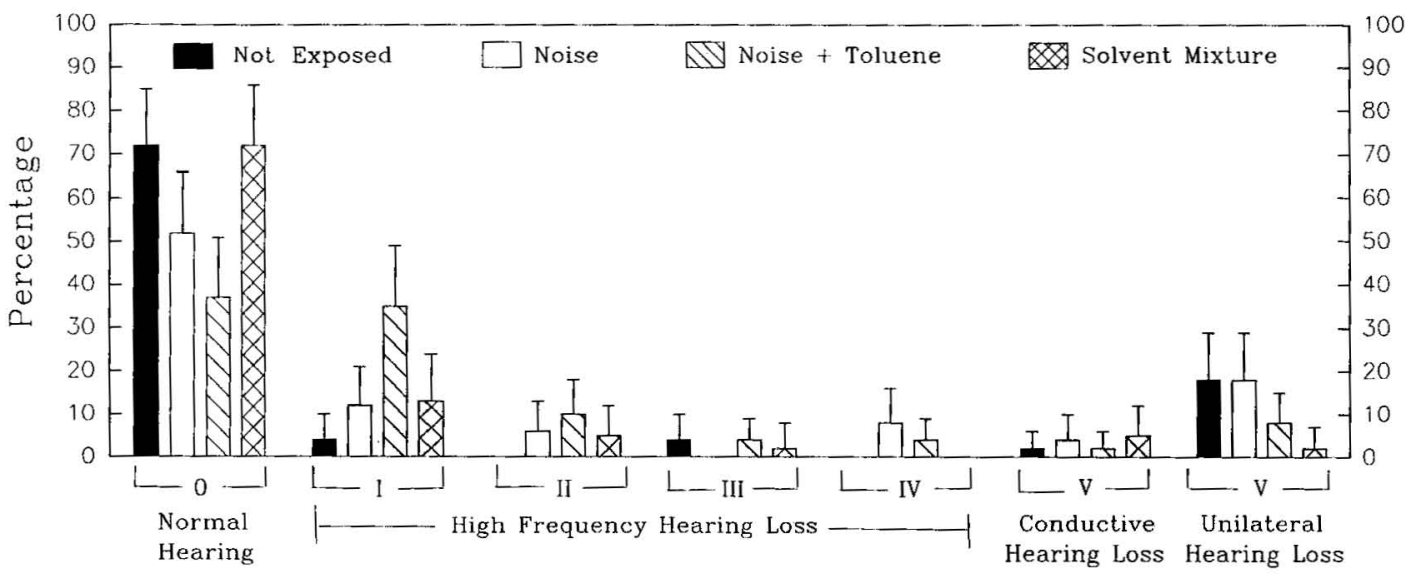

Audiometric Classifications

Figure 1. Classifications assigned to the audiograms of all of the subjects $(N=190)$ by exposure group. $T$ bars indicate upper bounds of the $95 \%$ confidence intervals. 
Table 6. Results of the multiple logistic regression for occupational hearing loss, by group.

\begin{tabular}{lcccccc}
\hline Variable & Beta & $\begin{array}{c}\text { Standard } \\
\text { error }\end{array}$ & $\mathrm{X}^{2}$ & P-value & $\begin{array}{c}\text { Relative } \\
\text { risk }\end{array}$ & $\begin{array}{c}95 \% \text { confidence } \\
\text { interval }\end{array}$ \\
\hline Intercept & -3.743 & 0.731 & 26.21 & 0.000 & & \\
Noise & 1.594 & 0.632 & 6.35 & 0.012 & 4.1 & $1.4-12.2$ \\
Noise + toluene & 3.182 & 0.664 & 22.94 & 0.000 & 10.9 & $4.1-28.9$ \\
Solvent mixture & 1.874 & 0.735 & 6.50 & 0.011 & 5.0 & $1.5-17.5$ \\
Employment time & 0.086 & 0.029 & 8.33 & 0.004 & 1.1 & $1.0-1.1$ \\
\hline
\end{tabular}

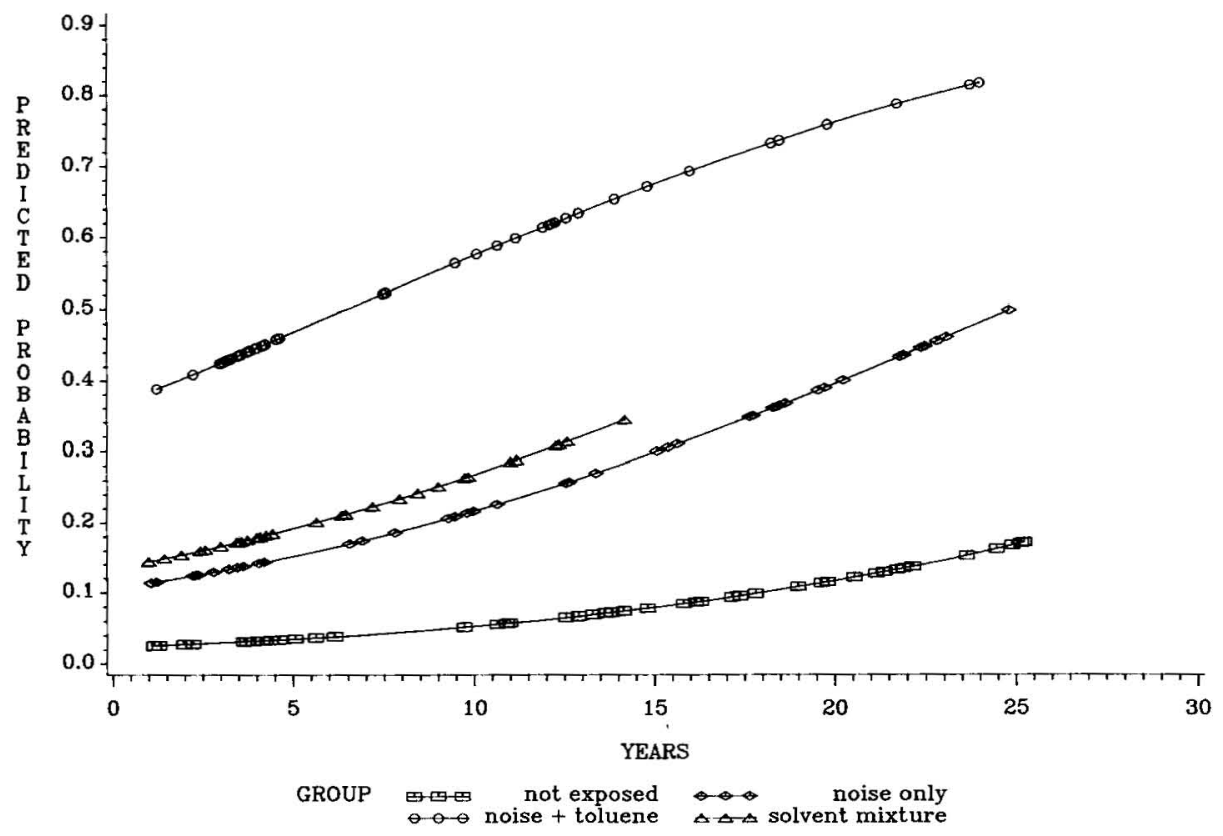

Figure 2. Predicted probability of developing a hearing loss, by exposure group and length of employment.

group for developing a hearing loss is illustrated in figure 2 .

\section{Acoustic reflex measurements}

The measures analyzed were absence or elevation of the reflex (in relation to expectation on the basis of values for normal ears or ears with cochlear hearing loss), presence of recruitment [observed when the difference between the pure tone and acoustic reflex thresholds was less than $60 \mathrm{~dB}(\mathrm{SL})]$, and presence of acoustic reflex decay (50\% reflex decay before $10 \mathrm{~s})$.

Initially, multivariate analyses of variance were performed using the following independent variables: group, ear, frequency of the stimulus, and stimulus presentation (contra- or ipsilateral). An overall significant difference was observed between the groups $(P<0.001)$. Subsequent analyses of variance (between and within subjects, with the subjects nested in groups) indicated significant differences between the groups regarding recruitment $(\mathrm{P}<0.05)$ and reflex decay $(\mathrm{P}<0.001)$, but not absence or elevation of reflex. Group contrasts regarding recruitment indicated that the mean percentage of cases in the noise-only exposed group was significantly higher than in any of the other groups. (See figure 3 for the percentage of cases and upper limits of the $95 \%$ CI values.) Group contrasts regarding reflex decay showed that the mean percentage of cases in the noise-plus-toluene group was significantly higher than in all of the other groups $(\mathrm{P}<0.001)$.

An overall interaction was found between group, frequency of the stimulus, and stimulus presentation $(\mathrm{P}<0.001)$. Reflex decay was the only outcome that was shown to interact significantly $(\mathrm{P}<0.01)$. (See figure 4 for the percentages and $95 \% \mathrm{CI}$ values.) At every test frequency the noise-plus-toluene group had a significantly higher percentage of reflex decay than the other three groups; the percentage of reflex decay was significantly higher for contralateral stimu- 
lation than for ipsilateral stimulation, and higher at $2000 \mathrm{~Hz}$ than at 500 or $1000 \mathrm{~Hz}$.

\section{Discussion}

To assess the workers' hearing status, pure tone audiometry and immittance audiometry were performed. Both noise and solvent exposures were measured. All of the subjects were interviewed by the first author (whose native language is Portuguese) with regard to health history, which focused on hearing, work history, and solvent and noise exposure.

The prevalence of high-frequency hearing loss found in the group exposed to noise and toluene simultaneously $(53 \%)$ was considerably higher than in the other groups (8\% in the unexposed group, $26 \%$ in the noise-only group, and $18 \%$ in the group exposed to a solvent mixture).

Significant differences were observed between the groups regarding the hearing classifications of $\mathrm{O}$ (normal hearing) and I (mild hearing loss). It was observed that the group exposed simultaneously to noise and toluene had a significantly higher percentage of cases of mild hearing loss than the other three groups. This finding raises the question of why the development of more serious hearing losses was not evident in the data. One possible answer for this question is that, since the workers who participated in the study had relatively short exposure times (averaging 5-13 years), they probably were not exposed long enough for the hearing loss to progress. Another possible answer is that the nature of the hearing loss was such that pure tone audiometry was not the appropriate test to assess the extent of the impairment.
High-frequency hearing loss was also examined with a multiple logistic regression for the estimation of relative risk adjusted for confounding variables. All of the exposure groups were shown to have significantly elevated risk ratios for hearing loss. These findings strongly suggest that chronic exposure to the studied solvents had a toxic effect on the auditory system. Moreover, it is very likely that an ototraumatic interaction between noise and toluene took place. If a group only exposed to toluene had been located, it would have been possible to investigate

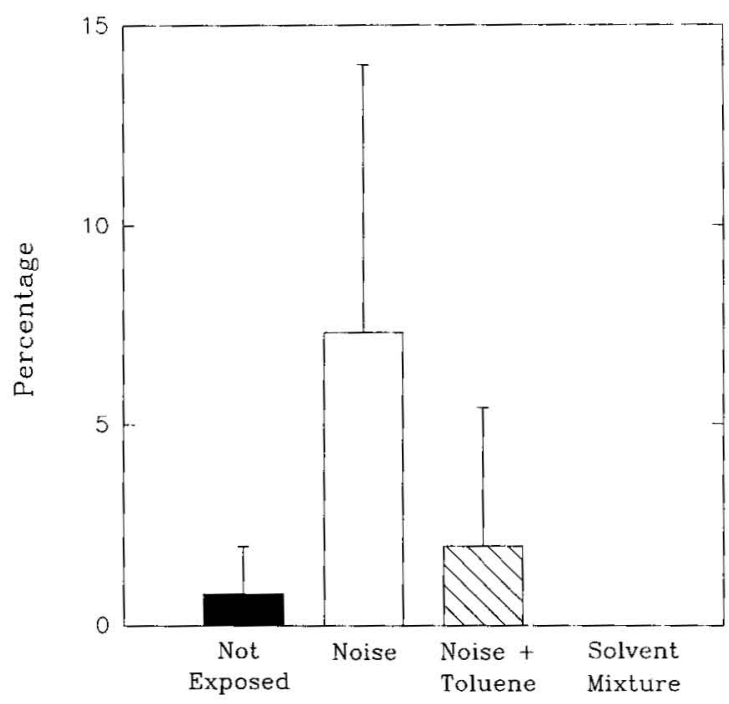

Figure 3. Percentage of ears with recruitment, by exposure group $(\mathrm{N}=161$, cases of conductive or unilateral hearing losses not included). T bars indicate the upper bounds of the $95 \%$ confidence intervals.

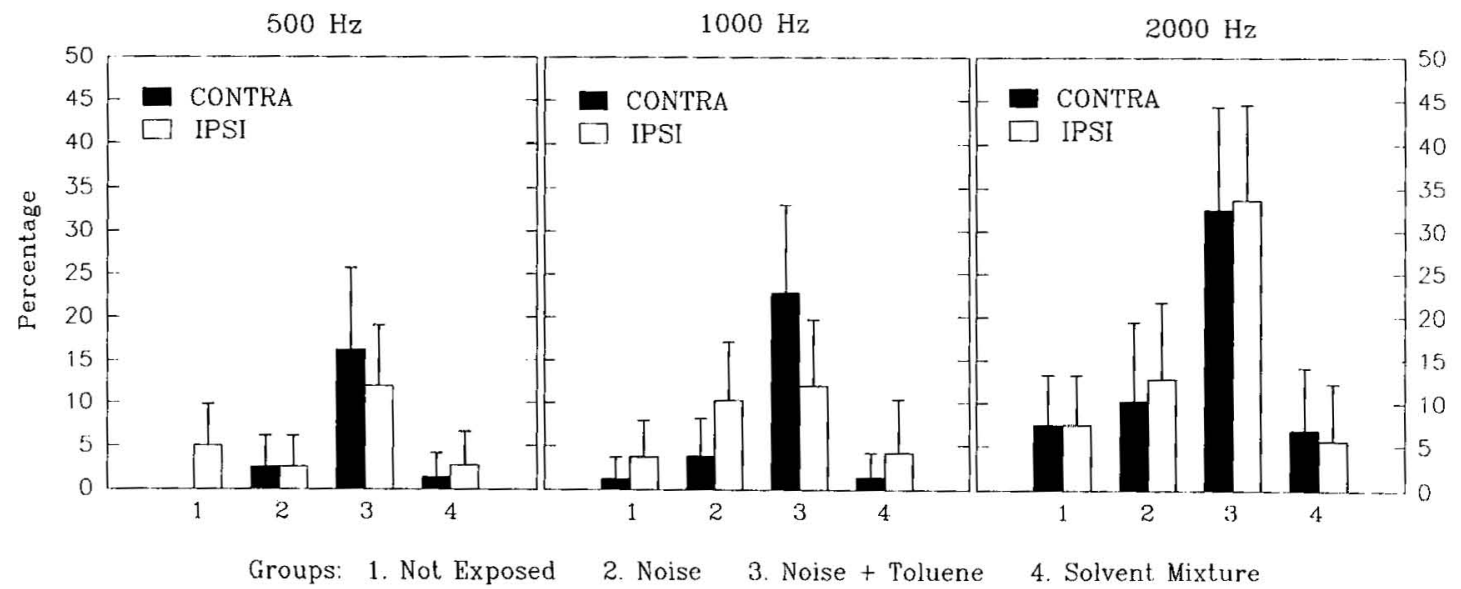

Figure 4. Percentage of ears with acoustic reflex decay, by exposure group $(N=161$, cases of conductive or unilateral hearing losses not included), test frequency, and stimulus presentation. T bars indicate the upper bounds of the $95 \%$ confidence intervals. 
the kind of interaction (additive or multiplicative) that might exist between noise and toluene.

Toluene ototoxicity has been discussed previously. Evidence indicating that toluene exposure affects hearing comes mainly from studies conducted with toluene abusers $(21-24)$ and animals $(8,27-31)$. In rats toluene interacted synergistically with noise. Hearing losses in groups of workers exposed occupationally to toluene have been reported previously $(7,32)$, but as a secondary finding.

Though our results of the hearing tests of the group exposed simultaneously to noise and toluene raises concern, the adjusted relative risk for hearing loss in the group exposed only to a solvent mixture has more critical implications. It was surprisingly high (relative risk 5.0) and higher than the risk for the noise-only group (relative risk 4.1). The solvent-only group was exposed to a mixture of toluene, xylene, and ketones. In rats, xylene has been reported to be a more powerful ototoxicant than toluene (33). The ketones present in the studied mixture (methyl ethyl ketone and methyl isobutyl ketone) are presumably less toxic than toluene and xylene (34-36). This finding suggests the urgent need for research on the hearing function of workers exposed to chemicals. The issue to be raised is whether hearing conservation regulations appropriately define who should and should not have their hearing tested.

Significant differences between the studied groups in the probable lesion site were observed through the determination of the occurrence of recruitment and acoustic reflex decay. In the present investigation the noise-exposed group had a significantly greater $(\mathrm{P}<0.05)$ percentage of cases of recruitment than did the other three groups. As has been seen in other studies, this finding suggests that the noise-only group had significantly more hearing loss of a cochlear origin than did the other three groups (37-41). In contrast, the noise-plus-toluene group had a significantly greater $(\mathrm{P}<0.001)$ percentage of cases of reflex decay at every test frequency than did the other three groups. Furthermore, the percentage of reflex decay for the contralateral stimulation was significantly greater than the ipsilateral stimulation. These findings suggest that the hearing losses in the noise-plus-toluene group had an intraaxial brainstem site of disorder. In such cases, when the uncrossed pathways are not involved on either side, the reflexes are typically normal to uncrossed stimulation and typically abnormal to crossed stimulation (37-39). Although such diagnostic statements cannot be made solely on the basis of these test results, it constitutes strong evidence about the probable lesion site. This observation does not eliminate the possibility of the hearing loss having a peripheral component.

Groups of workers with long-term occupational exposure to solvent mixtures have been evaluated with extensive audiological and vestibular test batteries $(6,10)$. Some of the subjects had a diagnosis of solvent-induced psychoorganic syndrome. The findings of pure tone audiometry, immittance audiometry (including reflex decay), and auditory brainstem response were essentially normal for age and noise-exposure history. Nevertheless, a significant abnormality was found in the discrimination of interrupted speech and cortical responses to frequency glides. The outcome of the audiological test batteries suggested that long-term exposure to solvent mixtures may give rise to lesions in the auditory pathways more central than the structures generating the auditory brainstem responses which differ from indications of this study. This contrast may be explained by the difference in the chemicals studied, exposure conditions, and the schedules and specific characteristics of the studied populations.

Abnormal brainstem auditory evoked responses and atrophy of the brainstem, cerebellum, and cortex have all been reported for chronic toluene abusers $(21-24,42,43)$. The regional distribution of toluene in the central nervous system may, in part, explain these clinical observations. Levels of inhaled toluene in specific brain regions have been measured in rats (44). Toluene was detected in all brain regions with the highest concentrations at the brainstem $(\mathrm{P}<0.05)$. A significant correlation for regional lipid content and maximum toluene concentration was demonstrated. The authors argued that low doses of toluene would be expected to affect lipid-rich regions of the central nervous system (medulla/pons and midbrain) preferentially and therefore lead to specific brainstem and cerebellar outflow signs. Higher doses would further suppress these areas, together with the cortex and subcortical structures.

In summary, the acoustic reflex findings of recruitment and reflex decay indicate that the hearing loss observed in the noise-plus-toluene group was not only more prevalent, but also different from the hearing loss observed in the noise-only exposed group. According to the reflex decay observations, the hearing loss observed in the group exposed simultaneously to both agents cannot be attributed merely to noise exposure. The acoustic reflex measurements strongly suggested that the site, as well as the mechanisms underlying the lesions of the group exposed to both agents, is probably different from those in the noise-only group. This possibility supports the idea that chronic occupational exposure to high concentrations of toluene, in combination with excessive levels of noise, might have a toxic effect on the auditory system beyond the inner ear.

\section{Concluding remarks}

In this study, simultaneous occupational exposure to excessive levels of toluene and noise were found to increase the predicted probability of developing a hearing loss significantly among rotogravure printers, when compared with a group of workers exposed to matching doses of noise. Furthermore, in the paint manufacturing industry, occupational exposure to a 
solvent mixture containing mainly toluene, xylene, methyl ethyl ketone, and methyl isobutyl ketone was also shown to increase the probability of hearing loss, with an adjusted relative risk greater than the one obtained in the noise-only group. The positive association between occupational exposure to solvents and hearing disorders raises serious concerns. Hitherto, occupational hearing conservation programs have not taken chemical exposures into consideration. Thus there may be numerous workers with unmet needs concerning hearing conservation.

In addition, the results from the acoustic reflex decay test suggest that there might be central auditory pathway involvement in the hearing loss observed among the rotogravure printers. This finding indicates that hearing testing not only could contribute as an early indicator of those who are more susceptible to the development of hearing loss, but also help identify those who are more susceptible to eventual neurotoxic effects of solvent exposure. The ideal procedure for studying and assessing the effects of solvents on hearing consists of a complete audiological test battery. Nevertheless, the tests used in the present study (pure tone and immittance audiometry) can be useful screening tools when hearing disorders are investigated in industrial populations in which complex exposure conditions occur.

\section{Acknowledgments}

This investigation was conducted at the University of Cincinnati, and approval was received from the University of Cincinnati for the study protocol and safety of human subjects.

This study has been supported financially by grants from the Brazilian Conselho Nacional de Desenvolvimento Científico e Tecnológico (National Council for Scientific and Technologic Development) and by the Division of Graduate Studies of the University of Cincinnati.

We would like to express our appreciation to Dr E Krieg, who gave us immeasurable assistance with the statistical analysis, and to Dr U de Paula Santos, Mr R Mazon and Ms TR Costa for their participation in the field study.

\section{References}

1. United States (US) Department of Labor, Occupational Safety and Health Administration. Final regulatory analysis of the hearing conservation amendment. Washington, DC: US Government Printing Office, 1981. (Report number 723-860/752 1-3.)

2. National Institute for Occupational Safety and Health (NIOSH). Proposed national strategies for the prevention of leading work-related diseases and injuries: noise-induced hearing loss. Cincinnati, OH: NIOSH, US Department of Health, Education and Welfare, Public Health Service, 1988.

3. Ginnold RE. Occupational hearing loss: compensation under state and federal programs. Washington, DC:
Environmental Protection Agency, 1979. (Report number 550/9-7 9-101.)

4. Barregård L, Axelsson A. Is there an ototraumatic interaction between noise and solvents? Scand Audiol 1984;13:151-5.

5. Bergström B, Nyström B. Development of hearing loss during long term exposure to occupational noise. Scand Audiol 1986;15:227-34.

6. Ödkvist LM, Arlinger SD, Edling C, Larsby B, Bergholtz LM. Audiological and vestibulo-oculomotor findings in workers exposed to solvents and jet fuel. Scand Audiol 1987;16:75-81.

7. Coscia GC, Tabaro G, Albera C, Tubino L, Morra B, Discalzi G, et al. Alterazioni vestibolari nell 'esposizione a toluene. Med Lav 1983;74:23-9.

8. Johnson AC, Juntunen L, Nylén P, Borg E, Hoglund G. Effect of interaction between noise and toluene on auditory function in the rat. Acta Otolaryngol 1988;105:56-63.

9. Morata T. Study of the effects of simultaneous exposure to noise and carbon disulfide on hearing. Scand Audiol 1989;18:53-8.

10. Möller C, Ödkvist LM, Thell J, Larsby B, Hydén D, Bergholtz LM, et al. Otoneurological findings in psycho-organic syndrome caused by industrial solvent exposure. Acta Otolaryngol 1989;107:5-12.

11. Dayal VS, Barek WG. Cochlear changes from noise, kanamycin and aging: II. potentiating effects of noise and kanamycin. Laryngoscope 1975;85 suppl 1:8-11.

12. Marques DM, Clark CS, Hawkins JE. Potentiation of cochlear injury by noise and ototoxic antibiotics in guinea pigs. J Acoust Soc Am 1975;57:S1(A).

13. Bone RC, Ran AF. Audiometric and histologic correlates of the interaction between kanamycin and subtraumatic levels of noise in the chinchilla. Trans Am Acad Ophthalmol Otolaryngol 1978;86:400-4.

14. Brown JJ, Brummet RE, Fox KE. Combined effects of noise and kanamycin. Arch Otolaryngol 1980;86: 394-400.

15. Mills $\mathbf{J H}$. A review of the environmental factors affecting hearing. In: AW Hayes, ed. Toxicology of the eye, ear, and other special senses. New York, NY: Raven Press, 1985:231 - 42 .

16. Boettcher FA, Henderson D, Gratton MA, Danielson RW, Byrne CD. Synergistic interaction of noise and other ototraumatic agents. Ear Hear 1987;8:192-212.

17. Lindgren $\mathbf{F}$. Clinical investigations of noise-induced temporary hearing loss. Göteborg: University of Göteborg, 1987.

18. Young JS, Upchurch MB, Kaufman MJ, Fechter LD. Carbon monoxide exposure potentiates high-frequency auditory threshold shifts induced by noise. Hear Res $1987 ; 26: 37-43$.

19. Rebert CS, Sorenson SS, Howd RA, Pryor GT. Toluene induced hearing loss in rats evidenced by the brainstem auditory evoked response. Neurobehav Toxicol Teratol 1983;5(1):59—62.

20. Pryor GT, Dickinson J, Feeney E, Rebert CS. Transient cognitive deficits and high-frequency hearing loss in weanling rats exposed to toluene. Neurobehav Toxicol Teratol 1983;5(1):53-7.

21. Lazar RB, Ho SU, Melen O, Daghestani AN. Multifocal central nervous system damage caused by toluene abuse. Neurology 1983;33:1337-40.

22. Malm G, Lying-Tunell U. Cerebellar dysfunction related to toluene sniffing. Acta Neurol Scand 1980; 62:188-90.

23. Metrick SA, Brenner RP. Abnormal brainstem auditory evoked potentials in chronic paint sniffers. Ann Neurol 1982;12:553-6.

24. Ehyai A, Freeman FR. Progressive optic neuropathy and sensorineural hearing loss due to chronic glue sniffing. J Neurol Neurosurg Psychol 1983;46:34951. 
25. Pereira CA. Surdez professional em trabalhadores metalurgicos: estudo epidemiologico em uma industria da Grande São Paulo [dissertation]. São Paulo: Universidade de São Paulo, 1978.

26. Miettinen OS. Theoretical epidemiology. New York, NY: John Wiley and Sons Inc, 1985:216-44.

27. Pryor GT, Dickinson J, Feeney E, Rebert CS. Hearing loss in rats first exposed to toluene as weanlings or as young adults. Neurobehav Toxicol Teratol 1984;6(2):111-9.

28. Pryor GT, Rebert CS, Dickinson J, Feeney E. Factors affecting toluene-induced ototoxicity in rats. Neurobehav Toxicol Teratol 1984;6:223-38.

29. Pryor GT, Howd RA, Uyeno ED, Thurber AB. Interactions between toluene and alcohol. Pharmacol Biochem Behav 1985;23(3):401-10.

30. Pryor GT, Howd RA. Toluene induced ototoxicity by subcutaneous administration. Neurobehav Toxicol Teratol 1986;8(1): 103 - 4 .

31. Sullivan MJ, Rarey KE, Conolly RB. Ototoxicity of toluene in rats. Neurotoxicol Teratol 1989;10:52530.

32. Lee B-R, Lee S-H, Lee K-M, Cho K-S, Ahn K-D, Kim $S-B$, et al. Dose-dependant increase in subjective symptom prevalence among toluene-exposed workers. Ind Health 1988;26:11-23.

33. Pryor GT, Rebert CS, Howd RA. Hearing loss in rats caused by inhalation of mixed xylenes and styrene. $J$ Appl Toxicol 1987;7(1):55-61.

34. International Labour Office (ILO). Encyclopaedia of occupational health and safety; vol 2. 3rd ed. Geneva: ILO, 1983.
35. Eckroth D, ed. Kirk-Othmer encyclopedia of chemical technology; vol 23. 3rd ed. New York, NY: John Wiley and Sons, 1983:246-73.

36. Seppäläinen AM. Neurophysiological approaches to the detection of early neurotoxicity in humans. CRC Crit Rev Toxicol 1988;18(4):245-98.

37. Jerger J, Jerger S, Mauldin L. Studies in impedance audiometry, normal and sensorineural ears. Arch Otolaryngol 1972;96:513-23.

38. Borg $E$. On the neuronal organization of the acoustic middle ear reflex: a physiological and anatomical study. Brain Res 1973;49:101-23.

39. Silman S, Popelka GR, Gelfand SA. The effect of sensorineural hearing loss and acoustic reflex threshold levels. J Acoust Soc Am 1978;64:1406-11.

40. Axelsson A. Diagnosis and treatment of occupational noise-induced hearing loss. Acta Otolaryngol Suppl 1979;360:86-7.

41. Lindgren F, Nilsson R, Axelsson A. The acoustic reflex threshold in relation to noise-induced hearing loss. Scand Audiol 1983;12:49-55.

42. Boor JW, Hurtig T. Persistent cerebellar ataxia after exposure to toluene. Ann Neurol 1977;2:440-2.

43. Fornazzari L, Wilkinson DA, Kapur BM, Carlen PL. Cerebellar, cortical and functional impairment in toluene abusers. Acta Neurol Scand 1983;67:319-29.

44. Gospe SM, Calaban DJ. Central nervous system distribution of inhaled toluene. Fund Appl Toxicol 1988; $11: 540-5$.

Received for publication: 22 July 1992 